\title{
Novel surgical techniques in female to male gender confirming surgery
}

\section{Miroslav L. Djordjevic}

Department of Urology, School of Medicine, University of Belgrade, Belgrade, Serbia

Correspondence to: Miroslav L. Djordjevic, MD, PhD. Department of Urology, School of Medicine, University of Belgrade, Tirsova 10 , 11000

Belgrade, Serbia. Email: djordjevic@uromiros.com.

\begin{abstract}
The current management of female to male (FTM) gender confirmation surgery is based on the advances in neo phalloplasty, perioperative care and the knowledge of the female genital anatomy, as well as the changes that occur to this anatomy with preoperative hormonal changes in transgender population. Reconstruction of the neophallus is one of the most difficult elements in surgical treatment of female transsexuals. While there is a variety of available surgical techniques, their results are not equally acceptable to all patients. The preference for a particular surgical technique mostly depends on the patient's desires and expectations. Nevertheless, the surgeon's duty is to fully inform the patient about all the advantages and disadvantages, as well as all complications that might occur after surgical procedure-and even to talk them out of a desired surgical technique if there are contraindications. Metoidioplasty is a technically demanding surgical procedure used in FTM transsexuals who desire a gender reassignment surgery (GRS) without undergoing a complex, multi-staged surgical creation of an adult-sized phallus. Metoidioplasty is viable in cases where the clitoris seems large enough after androgen hormonal treatment. Since the clitoris plays the main role in female sexual satisfaction, its impact on the outcome of FTM transgender surgery is predictable. Various free flaps have been reported for total phalloplasty, such as radial forearm flap, latissimus dorsi flap, anterolateral tight flap, different abdominal wall flaps, free deltoid flap, scapular free flap, sensate osteocutaneous free fibula flap, tensor fasciae latae, deep epigastric artery perforator flap and dorsalis pedis flap. The fact that there are so many techniques for penile reconstruction in cases of penis absence, proves that none of the above mentioned techniques succeeded in achieving the ideal goals of penis reconstruction. We will emphasize the most commonly used surgical techniques in genital confirmation in FTM transsexuals with reference to respective eligibility criteria for each procedure.
\end{abstract}

Keywords: Clitoris; female transgender; metoidioplasty; phalloplasty; reconstruction

Submitted Nov 24, 2017. Accepted for publication Mar 09, 2018.

doi: $10.21037 /$ tau. 2018.03 .17

View this article at: http://dx.doi.org/ 10.21037/tau.2018.03.17

\section{Introduction}

Gender dysphoria represents the incongruence between the sex assigned at birth and current gender identity, and may identify as male, female, or being elsewhere on the gender spectrum. Transgender individuals feel that gender assigned to them at birth is in some way "wrong" and therefore seek to take the opposite gender role (1). Gender dysphoria is becoming progressively acknowledged, especially in mainstream media. This kind of change in the public acceptance is leading more individuals to look for professional help. Several authors reported the prevalence of gender dysphoria among adults by examining the number of individuals turning to health services. However, these studies could underestimate the real prevalence since the individuals might be hesitant to seek medical care related to gender dysphoria (2). Also, there are differences between various aspects of gender dysphoric conditions. Prevalence and demographics differ depending on geographical location. Dhejne et al. showed a 2.5 -fold increase from 
0.16 to 0.42 per 100,000 annually from the first to the last decade over a period of 50 years [1960-2010] for FTM transgender patients in Sweden (3). A study in Belgium estimated the proportion of the population that had undergone sex reassignment surgery (SRS) from 1985 to 2003 through retrospective collection of data on procedures performed by gender teams. This study identified 412 Belgian-born "transsexuals", 292 MTF and 120 FTM (response rate $24 \%$ ), corresponding to prevalence estimates of 7.74/100,000 and 2.96/100,000, respectively (4).

Gender dysphoria requires a multidisciplinary approach and treatment, where the only real management consists of "adjusting the body to the mind" (5). Multidisciplinary approach incorporates psychiatric assessment, followed by hormonal treatment lead by an endocrinologist, "the real life" test and, as the last step in the treatment, the gender reassignment surgery (GRS). The seventh version of the Standards of Care of the World Professional Association of Transgender Health (WPATH) offers flexible guidelines for the treatment of people experiencing gender dysphoria and describes the criteria for surgical treatments (6). Patients undergoing GRS of their choice are required to provide two recommendation letters from certified psychiatrists and a gender specialist along with the confirmation of having been on hormonal therapy prescribed by an endocrinologist for at least a year. GRS refers to all surgical procedures that a patient wants to undergo in an attempt to become as similar as possible to the opposite gender. SRS is a part of the GRS and refers only to the genital reconstruction (7).

When choosing the gender confirmation surgery, the patient must be mindful of the desired postoperative result they wish to achieve and surgical options available in their case. This is the point where the patient must undergo a meticulous preoperative consultation and examination by the surgeon performing the surgery. In most cases, patients have already defined their desires and preferences regarding surgery. However, it is a surgeon's duty to present all surgical options, their advantages and disadvantages, as well as surgical risks and expected results. A person's anatomy can sometimes be a limiting factor for specific kind of surgery, and a detailed preoperative plan and informed consent should be defined together with the patient, in order to prevent unreal expectations. Also, a detailed discussion with a psychologist is necessary to prevent the possible disappointment following surgery.

The most commonly performed procedures in FTM transsexual patients are bilateral mastectomy with male chest contouring, removal of female genitalia which includes total hysterectomy with bilateral oophorectomy and genital reconstructive surgery with two options: metoidioplasty or total phalloplasty. Reconstruction of the neophallus in FTM patients is a great challenge because no optimal replacements are available to recapitulate erectile, fascial, or urethral tissue (8). Desired outcomes of metoidioplasty include voiding in the standing position, creation of an aesthetically pleasing phallus, and preservation of clitoral sensation. Additional goals of total phalloplasty include development of erogenous and tactile phallus sensation, minimization of donor-site morbidity, and the ability to engage in penetrative sexual intercourse (9).

\section{Metoidioplasty}

Metoidioplasty is one of the most popular surgical techniques for creating neophallus in female transsexuals. The main goal of metoidioplasty is to give the patient "male-looking genitalia" and the possibility to void in standing position. Durfee and Rowland first reported the possibility of using the clitoris for penile substitution in female transsexuals. The techniques have been refined since then, defining this surgical transformation as metoidioplasty, derived from the Greek words 'meta''toward' and 'oidion'-'male genitalia' (10). In this type of procedure, the hormonally enlarged clitoris is used to create a small neophallus. The scrotum is created from the labia majora with insertion of two testicular prostheses. As the urethral plate remains intact, the neophallus was usually small and curved. Hage reported a modification of metoidioplasty characterized by urethral lengthening. New urethra was created from the urethral plate and a labia minora skin flap. The urethral plate was divided at the level of the urethral opening. Since the dissection was in the proximal-to-distal direction, there was a risk of compromising the vascularization of the mobilized plate. This type of dissection lead to a high complication rate. For all of these reasons, Hage came to the understanding that 2.6 procedures were necessary to achieve optimal results in this type of surgery (11). Perovic et al. [2003] reported good results of metoidioplasty in 22 patients, with complications related to urethral reconstruction in 5 cases (12). Recently, Belgrade centre reported their original technique of neophalloplasty/metoidioplasty, based on the repair of most severe forms of hypospadias with goal to improve results of urethral reconstruction and minimize complication rate in one stage repair $(13,14)$. This work later resulted in many modifications of this original technique, aimed at 


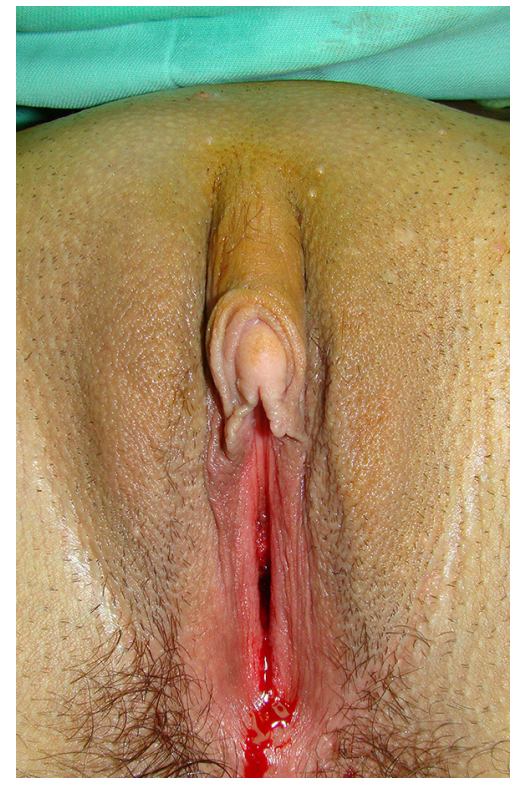

Figure 1 Preoperative appearance. Clitoris is hormonally enlarged.

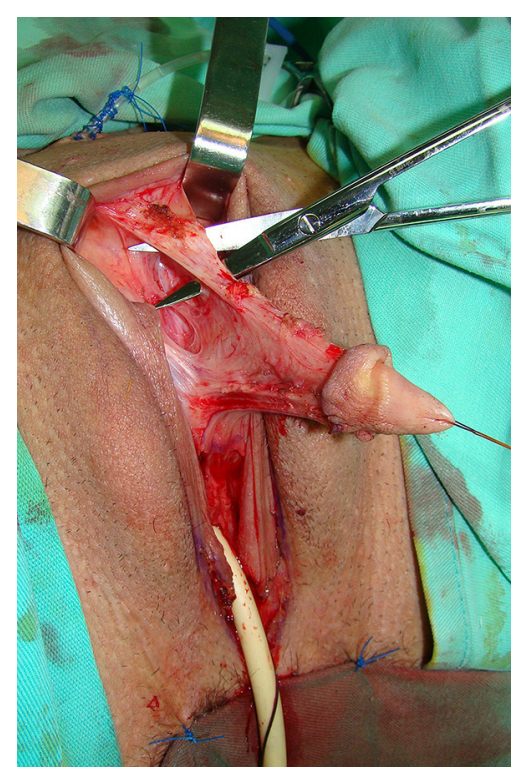

Figure 2 Clitoral ligaments are completely divided up to the bone attachment enabling maximal lengthening of the clitoris. It should be done carefully to prevent injury of the neurovascular bundle that runs under the ligaments.

changing the feminine appearance of the external genitalia to a more masculine morphology and at allowing voiding while standing $(15,16)$. The novel technique is based on the similarity in penile and clitoral anatomy and the statement first introduced by Williams, that the clitoris is thus in many details a small version of the penis, but that it differs basically in being entirely separate from the urethra (17) (Figure 1).

This one stage procedure includes the removal of internal female genitalia, comprising hysterectomy, adnexectomy and vaginectomy, the creation of a neophallus from the clitoris, and the reconstruction of the urethra and scrotum. The approach is based on our experience and satisfactory results in numerous cases of severe hypospadias associated with penoscrotal transposition $(18,19)$.

Preoperatively, patients are advised to use dihydrotestosterone gel and vacuum erection pump twice daily for a period of 3 months before surgery, for additional clitoral enlargement. Clitoral dissection starts with a circular incision beneath the glans, at the border between the inner and outer layer of the clitoral prepuce, and continues around the urethral plate and native urethral orifice. Clitoral degloving continues with division of the fundiform and suspensory clitoral ligaments including de-attachment from the pubic bones (Figure 2). Additional lengthening and straightening are achieved by dissection of the short urethral plate positioned ventrally between glans and female urethral opening. Dissection should be performed carefully to prevent injury of the spongiosal tissue around the urethral plate and extreme bleeding. It includes mobilisation of the bulbar muscles that will be used for the upcoming urethral reconstruction. Since the urethral plate is short and causes ventral chordee, it has to be divided. All of these manoeuvres enable a complete straightening and lengthening of the clitoris (Figure 3).

Urethral reconstruction presents the most difficult procedure in metoidioplasty. Reconstruction of the neourethra begins with the reconstruction of its bulbar part. One of the main advantages of the novel technique lies in the simultaneous removal of the vaginal mucosa and use of the periurethral vaginal tissue for the reconstruction of the bulbar urethra. As the urinary stream is the strongest at this location, this site presents with a high risk of fistula formation in the postoperative period. Joining the two bulbar muscles over the lengthened urethra and additional covering with surrounding tissue can successfully prevent fistula formation. Further urethral reconstruction is based on formation of a new urethral plate. Buccal mucosa graft presents a gold standard in urethral reconstruction in the recent decades. The graft is tough, elastic, easy to harvest, easy to handle, and leaves no visible scar at the donor site. Their histological composition makes them good grafting material (20). The size of the graft depends on the size 


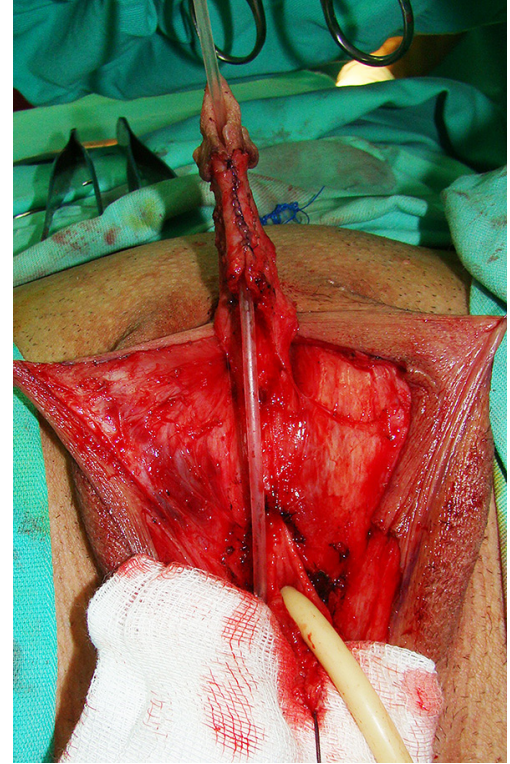

Figure 3 Ventrally, the short urethral plate is divided creating a gap between its ends. This maneuver completely straightens the clitoris.

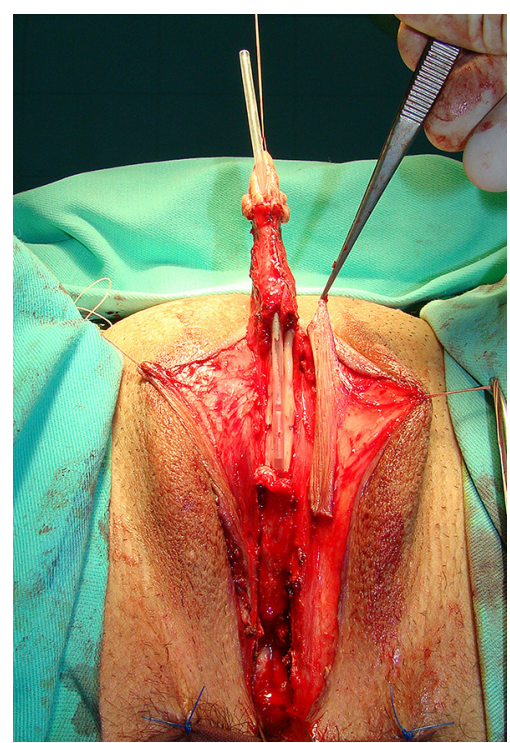

Figure 4 Distal part of urethral plate is tubularized creating distal neourethra. Bulbar part of the urethra is formed by joining the anterior vaginal wall flap and the proximal part of the urethral plate. The gap between the two parts is filled with a buccal mucosa graft. Fasciocutaneous flap is harvested from the left labia minora, to be joined with the buccal mucosa graft.

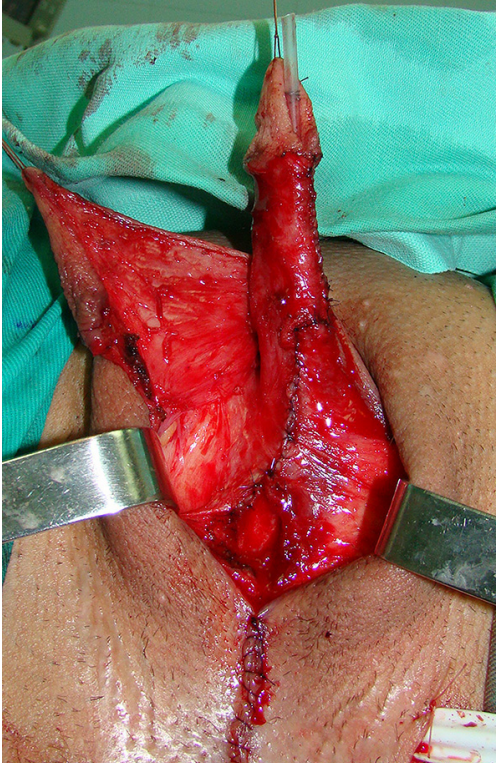

Figure 5 Neourethra is formed by combined vascularized genital flaps and buccal mucosa graft.

of the defect between the newly-created bulbar urethra and the glans. The graft is placed as a dorsal inlay on corporal bodies and quilted, enabling better graft survival. Additionally, a well-vascularized recipient site provides a good blood supply and prevents contractions of the graft. Urethral reconstruction can be accomplished either by using a longitudinal dorsal clitoral skin flap button-holed ventrally, or a flap harvested from the inner surface of the labia minora. Recently, we published our comparative study and found that labial flap combined with buccal mucosa graft offers the best results with less than $7 \%$ complication rate (13). In both types of urethral reconstruction, well vascularized tissue completely covers all suture lines, thus preventing fistula formation (Figures 4,5).

Scrotoplasty is performed by joining both labia majora in the midline and inserting two silicone testicle implants of appropriate volume, in order to fit the patient's anatomy. In most cases, testicular implants with $21 \mathrm{~mL}$ volume are placed. Considering that this technique uses a large portion of clitoral skin, the remaining labia minora is always available for covering of the lengthened neophallus. Reconstruction of the skin with well-defined penoscrotal angle offers a real masculine appearance of the external 


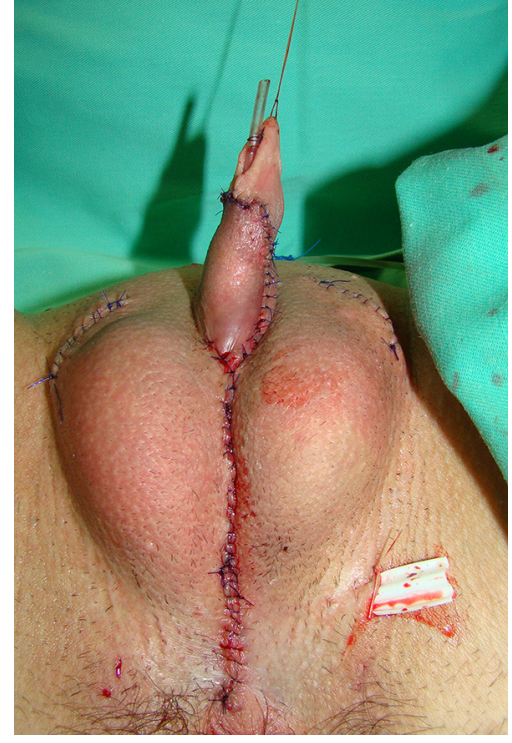

Figure 6 Appearance after metoidioplasty. Two testicle implants are inserted into the scrotum created from the joined labia majora.

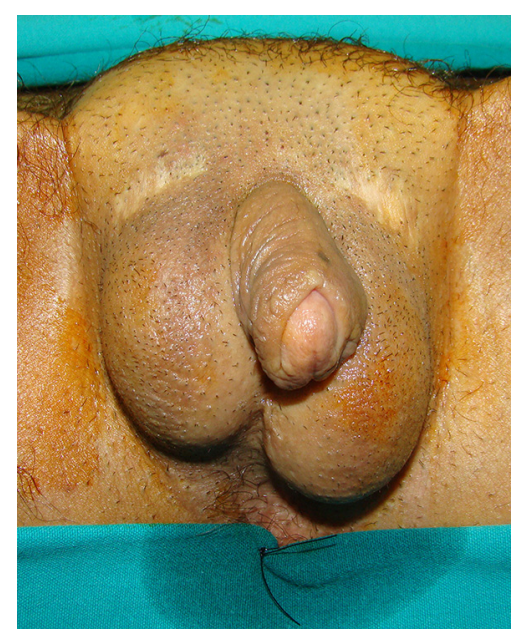

Figure 7 Outcome 2 years later. Good appearance of new male genitalia is achieved.

genitalia (Figure 6).

Broad spectrum antibiotics and anticholinergic drugs are prescribed while the catheter is in place. Urethral stent is removed 10 days after surgery, and suprapubic tube is left indwelling for 3 weeks. Postoperatively, use of the vacuum device is advised to prevent retraction of the neophallus, starting 3 weeks after surgery, for a period of at least 6 months, combined with a phosphodiesterase type- 5 inhibitors treatment.
Between September 2002 and January 2017, we surgically treated 557 patients by one stage metoidioplasty with the mean age of 32 years (ranging, 18-62 years). Hysterectomy and bilateral salpingo-oophorectomy were performed at the same time as metoidioplasty in 62 patients. Urethral reconstruction with buccal mucosa graft combined with fasciocutaneous clitoral or labial flap was performed in 51 and 506 cases, respectively. Neophallic length ranged from $4-10 \mathrm{~cm}$ in maximal extension (median, $5.6 \mathrm{~cm}$ ). Erection of the neophallus was present in all patients and none of the patients reported difficulties or other problems related to sexual arousal, masturbation or orgasm. Postoperatively, all patients were evaluated by a psychologist, and according to their self-reports, the majority were pleased with the appearance of their new male genitalia (508 "completely satisfied", 49 "somewhat satisfied").

Minor complications, such as dribbling and spraying during voiding occurred in 33\% and resolved spontaneously 3 months after the surgery without the need for surgical revision. Urethral fistula in 39 and stricture in 8 patients were successfully repaired by minor surgical revision. Urethral fistula was repaired by simple excision of the fistula and covering with the available local vascularized tissue. Repair of urethral stricture included anastomotic or buccal mucosa graft urethroplasty. Other complications that required additional surgical intervention were testicular implant rejection in 7 patients, as well as testicular implant displacement in 23 patients (13-16).

One stage metoidioplasty has been recognized as a method of choice for genital confirming surgery in FTM transsexuals who wish to have a male-like appearance of their genitals, without undergoing complex and multistage procedures (Figure 7). The main disadvantage of metoidioplasty is that the created neophallus is mostly inadequate in length to allow vaginal penetration, and all patients should be informed of this fact prior to surgery. However, this does not present a limitation for further total phalloplasty.

\section{Phalloplasty}

Phalloplasty, or surgical construction of an adult size penis, in FTM transsexual patients still presents one of the most difficult surgical procedures in genital reconstructive surgery. Moreover, the procedure poses considerable challenges for all surgeons performing the SRS because of the particular psychological implications and patients' demands. Phallic reconstruction should ideally create 
an aesthetically pleasing phallus with sufficient length for vaginal penetration, which has tactile and erogenous sensibility, enables voiding in standing position and with acceptable donor site morbidity.

Since total penile reconstruction was first reported, there have been constant endeavors to develop an ideal technique for phalloplasty that can fulfill all the desired objectives (21). In the past, many authors described their experience with variants of local flaps, generally based on the inferior epigastric vessels, but during 1980s' different microsurgical free flaps became very popular and entered into common use for FTM confirmation surgery. Despite the fact that various phalloplasty techniques were described in recent decades, using pedicle or free transfer flaps, the most commonly used flaps in FTM transsexuals are radial free forearm and free musculocutaneous latissimus dorsi flap that will be discussed in detail (22-28). We are still searching for ideal phalloplasty, that will satisfy all patient's requirements. Tissue engineering and penile transplantation seem promising, but there are still many technical and bioethical issues to be resolved.

Forearm phalloplasty involves the construction of a neophallus from forearm tissue and its attachment in the appropriate position to approximate a male penis. The neophallus is generally formed from tissue taken from the inner forearm skin (on the patient's nondominant side) as well as vaginal tissue to form the neourethra. The use of the radial forearm free flap is well described by a great number of different authors in genital reconstructive surgery $(22,23,25)$. This flap is supplied by the radial artery and by the paired vena comitantes. Sensation of the flap is based on medial or lateral antebrachial cutaneous nerves. The skin is thin, pliable, and usually hairless, while the vascular pedicle may be up to $18 \mathrm{~cm}$ in length and the vessel diameters are usually large (2-4 mm).

The most popular approach is "tube within a tube" phalloplasty. Part of the flap along the ulnar border of the forearm, free of hair, is tubed inward around a Foley catheter, creating the neourethra. The adjacent radial strip of skin is deepithelialized to allow the flap to be rolled up. The remaining part of the of the flap is wrapped around the neourethra, creating a tube. The pedicle, which consists of radial artery, venae comitantes, lateral cutaneous nerve and cephalic vein, is dissected carefully and left attached while a second surgical team prepares the recipient groin vessels. Once the recipient site is ready, the radial artery flap is transferred to the groin. Vascular anastomosis of the radial artery end-to-side with the femoral artery, and of the cephalic vein end-to-end with the long saphenous vein, are performed. The lateral cutaneous nerve of the forearm is joined to the ilio-inguinal nerve. The neourethra is anastomosed to the advanced female urethra. The clitoris remains undisturbed at the base of the new phallus, retaining its sensation (22).

According to Ghent group, the most common complications were related to urethroplasty and reported in 126 of 316 transmen (40\%). Urethral fistula requiring revision surgery occurred in $17 \%$ of the patients. Other cases with urethral complications, either fistula or stricture, were treated conservatively. Authors reported implantation of erectile prosthesis in 143 patients with a complication rate of $41 \%$ requiring surgical revision. Authors concluded that a complete phallic reconstruction with the erection device can never be performed in a single operation and recommended insertion of penile prostheses after complete healing of the neophallus (29). Garaffa et al. reported satisfactory results in 112 of 115 FTM transgenders who underwent radial forearm phalloplasty. Good sensation was noted in $86 \%$. Urethral fistula in 9 and stricture in 20 patients were treated by revision surgery and voiding while standing was achieved in $99 \%(30)$.

Advantages of this procedure include the creation of a sensate neophallus with complete urethral lengthening at the same stage. Consistent arterial anatomy and long vascular pedicle with good diameter of the vessels enables easier microsurgical anastomoses. Disadvantages of this technique include the small size and circumference of the neophallus, as well as visible donor site scar. Additionally, smaller volume of the neophallus presents a limitation for insertion of two cylinders of the penile prostheses.

The musculocutaneous latissimus dorsi flap, first described by Baudet, has a reliable and suitable anatomy (good size, volume and length of neurovascular pedicle) to meet the esthetic and functional requirements of phallic reconstruction (31). This is our method of choice and we have published our first results with this technique in phallic reconstruction in boys with epispadias, micropenis and intersex disorders (24). In gender confirmation surgery, the technique includes the removal of internal female genitalia such as hysterectomy, adnexectomy and vaginectomy, followed by creation of a neophallus from the latissimus dorsi musculocutaneous flap, fixation at the pubic region, anastomosis with the blood vessels at recipient site and scrotoplasty. Additional stages include neophallic urethral lengthening and penile prosthesis implantation and can be performed several months after the first stage. Preoperatively, the donor, non-dominant, site region needs to be treated by 


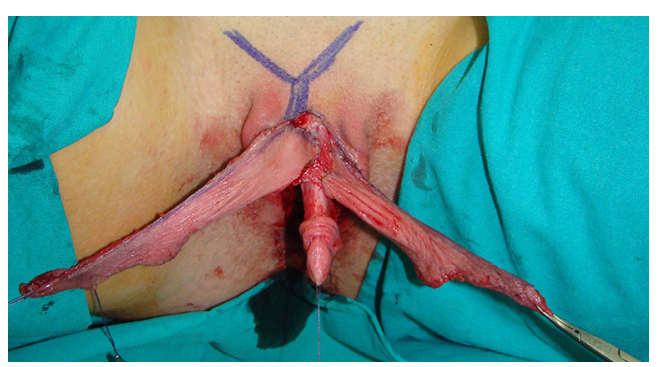

Figure 8 Both labia minora and hairless clitoral skin are harvested to create a very long fasciocutaneous flap for urethral lengthening.

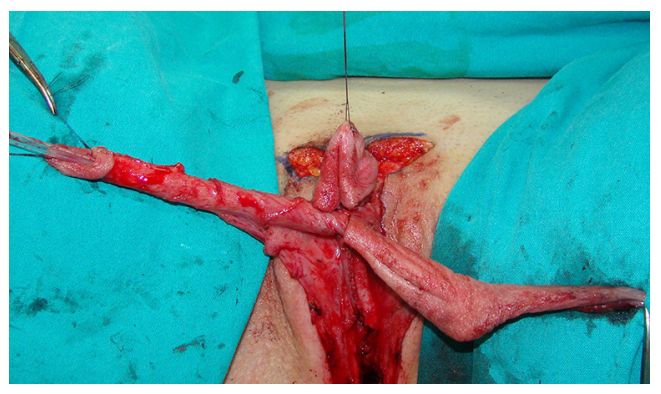

Figure 9 Urethra is lengthened by tubularization of the genital flap.

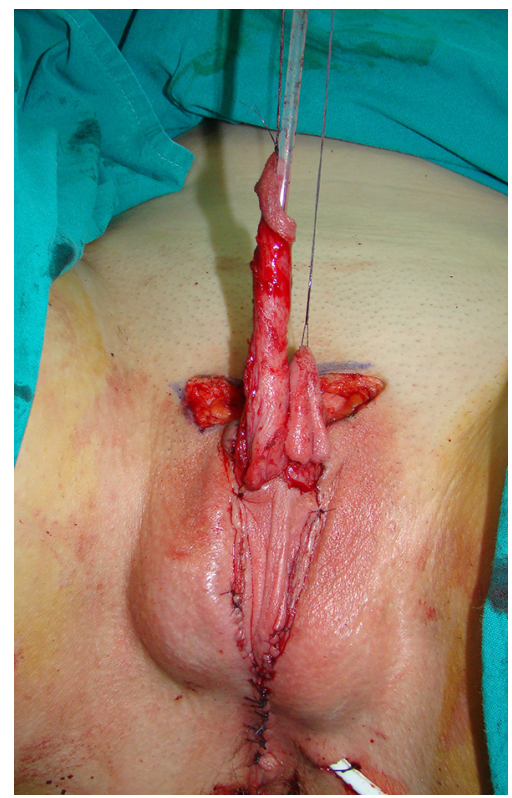

Figure 10 Scrotum is created and testicular implants are inserted. Clitoral glans is placed at the base of the recipient area. a professional massage which will improve skin elasticity and thus enable direct closure of the donor site after harvesting of the flap. The massage is performed continuously for at least three months before the surgery $(32,33)$.

Clitoral lengthening and repositioning is performed in the same way as previously described for metoidioplasty. Urethral reconstruction begins with the reconstruction of the bulbar part of the urethra. Remaining part of the anterior vaginal wall is anastomosed with the remaining urethral plate, forming the bulbar part of the urethra. Further urethral reconstruction includes using all available genital tissue, both labia minora, and hairless clitoral skin. The inner surface of both labia minora is dissected to create a flap with appropriate dimensions without detachment from the outer labial surface (Figure 8). This allows for excellent vascularization of the flap. Flaps are joined to create a tube and to lengthen urethra from its bulbar part. The urethra is lengthened further using available clitoral skin (Figure 9). Both varieties of flaps, clitoral and labial, have fine supportive tissue that prevents fistula formation. Vaginal space is approximated and perineum is fashioned to resemble the male perineum. Both labia majora are joined in the midline over the neourethra creating the onesac scrotum. Silicone testicle prostheses are inserted in the newly formed scrotum, completing scrotoplasty (Figure 10).

The patient is placed in the lateral position (upper torso placed in a full lateral position at $90^{\circ}$ and the pelvis at a $30^{\circ}$ angle) to provide access to the groin and simultaneous approach to the recipient site and blood vessels (Figure 11). Flap elevation starts with an incision of the anterior skin margin down to the deep fascia, and the plane is developed between the latissimus and anterior serratus muscle, using sharp and blunt dissection. The flap is divided inferiorly and medially, cauterizing the large posterior perforators of the intercostal vessels, and then lifted to expose the neurovascular pedicle. The pedicle, surrounded by fatty tissue, is identified and dissected proximally up to the axillary vessels. The thoracodorsal nerve is identified and isolated proximally for $3-4 \mathrm{~cm}$, preserving its vascularization. The flap is completely elevated except for the neurovascular bundle, which is not transected until the recipient vessels and nerve have been prepared for microanastomosis. Latissimus muscle is fixed at several points to the edges of the skin to prevent layer separation 


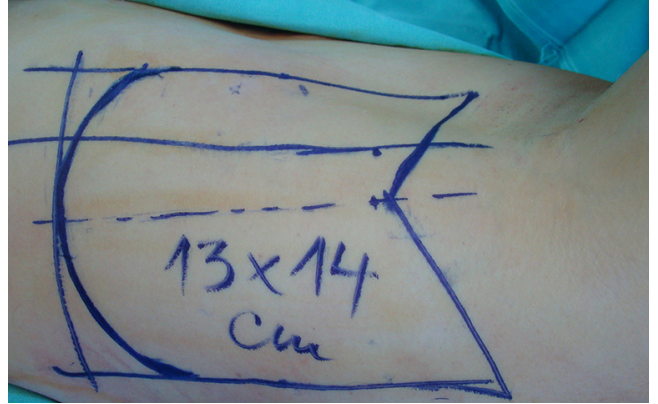

Figure 11 Design of the latissimus dorsi musculocutaneous flap.

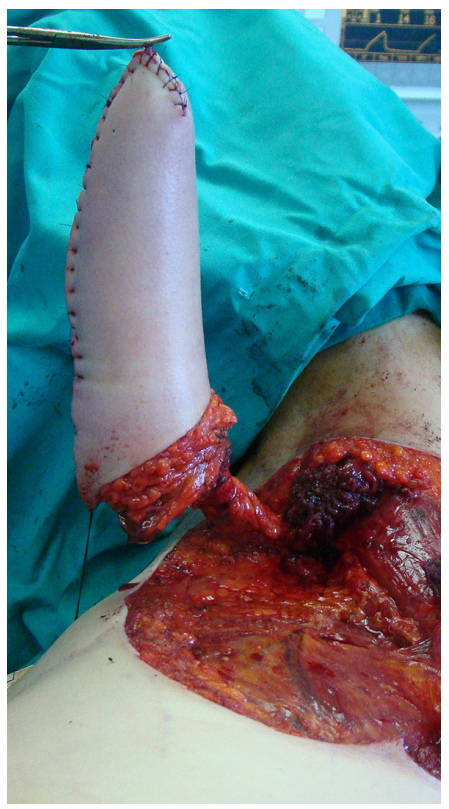

Figure 12 Neophallus is created by tubularization of the latissimus dorsi flap.

during further dissection. The flap is tubularized creating the neophallus and the distal end is closed to create the glandular part of the neophallus (Figure 12). Entirely constructed neophallus is detached from the axillar region after clamping and dividing the subscapular artery, vein and thoracodorsal nerve at their origin, in order to achieve maximal pedicle length. The donor site is approximated and closed directly after adjacent undermining. In case of significant tension, the defect is partially covered by Thiersch skin transplants.

After identifying all neurovascular structures at the recipient site, the thoracodorsal vessels and nerve are

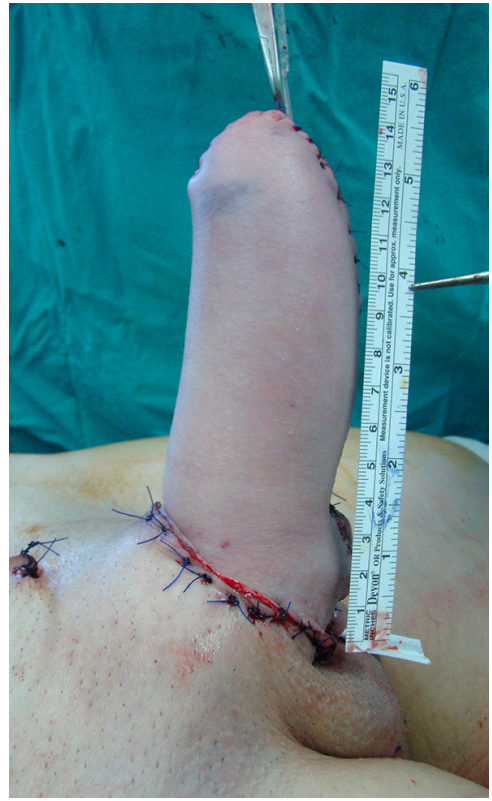

Figure 13 Final appearance after microvascular anastomosis and fixation of the neophallus at the genital region.

divided, the neophallus is transferred to the pelvic region and a microsurgical vascular anastomosis is performed immediately. The neophallic base is fixed to the skin at the recipient site (Figure 13).

Second and third stage include further urethral lengthening and insertion of penile prosthesis. Urethral reconstruction i.e., creation of the neophallic urethra is performed 6 months after the phalloplasty. Buccal mucosa grafts are harvested from both inner cheeks and lower lip. Previously, neophallus is opened in the midline to create a space for buccal mucosa placement. Subsequently, the grafts are placed and quilted on the ventral side of the neophallus starting from the advanced urethral meatus to the tip of the glans. Three or more months later, newly created urethral plate is tubularized to form the distal part of the new urethra. Two types of penile prostheses, semirigid and inflatable, are used for insertion into the neophallus, enabling penetrative sexual intercourse. Semilunar incision is made at the dorsal side of the neophallus. Hegar dilators are used to create space for the prosthesis to be inserted. The prosthesis is covered with vascular grafts imitating tunica albuginea to prevent protrusion through the glans. Additional fixation to the periosteum of the inferior pubic rami is performed (Figures 14,15).

Broad-spectrum antibiotics were recommended to 


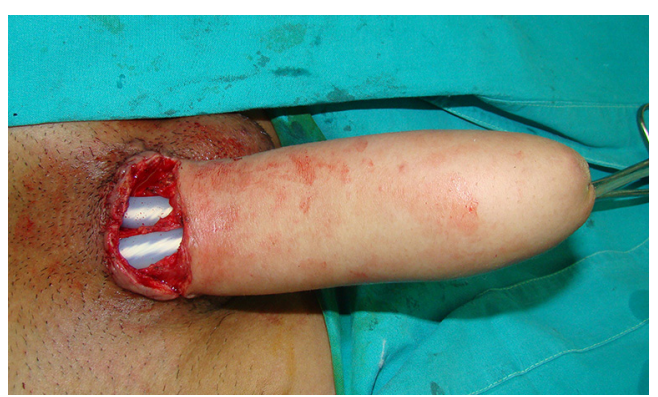

Figure 14 Malleable penile prosthesis is inserted by dorsal approach preventing injury of the phallus vascular pedicle or the urethra.

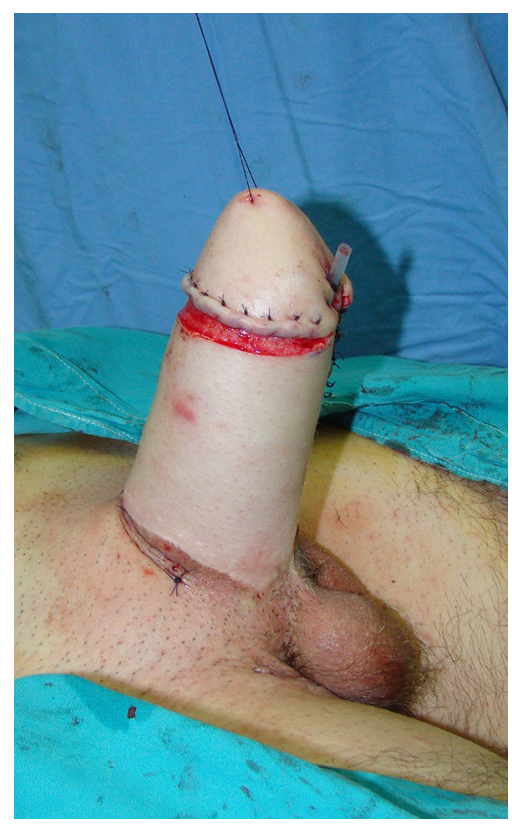

Figure 15 Appearance at the end of second stage with glansplasty, urethral lengthening and inserted penile implants.

prevent infection after each of the stages. In the first stage of phalloplasty, special dressing and fixation of the neophallus in elevated position are used to prevent pedicle kinking. Urethral reconstruction is followed by suprapubic urine derivation for a period of 3 weeks to allow satisfactory healing of the neourethra. Special care should be taken after penile prosthesis implantation to prevent infection and its rejection.

In both types of phalloplasty, total flap necrosis is extremely uncommon in experienced hands. When flap is completely lost, another type of pedicled or free flap is used in the next stage to create a neophallus.
Between 2007 and 2017, a total of 137 transgender patients underwent MLD phalloplasty at our Centre. In $103 / 137$ patients phalloplasty was performed as a primary procedure, while in $27 / 137$ patients, it was performed after previously performed metoidioplasty. Another seven patients underwent MLD phalloplasty as a reversal surgery due to regret following male to female transition. The average size of the neophallus was $15 \mathrm{~cm}$ (ranging from 12 to $21 \mathrm{~cm}$ ) and $13 \mathrm{~cm}$ in girth (ranging from 12 to $15 \mathrm{~cm}$ ). In seven cases split thickness skin graft was used to cover the ventral side of the neophallus preventing high suture pressure and possible compartment syndrome.

In our series, less than $20 \%$ of patients reported tactile sensation of the neophallus, confirming one of the main drawbacks of this procedure. The majority of sensation is limited to the clitoris, which is incorporated at the base of the neophallus, and the proximal part of the urethra, which is created from the hairless flaps of genital skin (clitoral skin and labia minora skin).

Total length of the reconstructed urethra, during the first stage, was measured during the surgery and ranged from $12.1-19.7 \mathrm{~cm}$ (median, $13.8 \mathrm{~cm}$ ). In $80 \%$ of patients, the urethral opening was located in the proximal third of the neophallus. In eight patients, the neourethral opening was placed in the middle section of the neophallus. In the remaining 16 patients, the newly created urethra was opened at the base of the neophallus, since there wasn't enough vascularized genital hairless skin for more lengthening. Neophallic urethral reconstruction by either one or two-stage buccal mucosa graft tubularization was performed in 82 patients.

We used two types of penile prostheses in 48 of our patients. Malleable prostheses were implanted in 29 patients and tri-component inflatable prostheses were used in the remaining 19. There was more interest in penile prostheses implantation, but the high cost of the prostheses presented a limiting factor for the patients in our series. A psychologist or a psychiatrist evaluated patients postoperatively. According to patients' self-reports, the majority were pleased with the aesthetic appearance of their male genitalia (101 "completely satisfied", 18 "somewhat satisfied"). Erogenous sensation based on clitoral stimulation was reported by all 119 patients. None of the patients reported problems or difficulties in sexual arousal, masturbation or orgasms. In all patients who had received penile implants, sexual intercourse with complete penetration was totally adequate. 


\section{Summary}

Genital confirming surgery in FTM transsexuals is usually a multistage procedure. The main goal is to create malelike genitalia of an adult male that will enable voiding in standing position, satisfactory esthetic appearance and good sexual function. Metoidioplasty presents one of the variants of phalloplasty. This is a one stage, safe and timesaving surgical procedure. It presents an alternative for patients who look for a change in their external genitalia toward the male-like, avoiding the extensive scarring that is always associated with other total phalloplasty techniques. Advanced urethroplasty using combined buccal mucosa graft together with fasciocutaneous genital flaps presents the main advantage of one stage metoidioplasty. Additionally, it minimizes postoperative complications, which is very important in choosing a surgical procedure. Metoidioplasty enables voiding while standing, but the neophallus is not fully adequate as it is too small to allow for sexual intercourse.

Total phalloplasty represents a surgical procedure of creating a neophallus from extragenital tissue and is considered one of the most challenging and demanding procedures in reconstructive surgery. Phalloplasty in male transgenders is considered to ideally create an aesthetically pleasing phallus with sufficient length for vaginal penetration, which has tactile and erogenous sensibility, which enables voiding in standing position and has acceptable donor site morbidity. Despite the fact that there are many alternatives for phalloplasty and the radial free forearm flap technique presents the gold standard, our preference is musculocutaneous latissimus dorsi flap technique. This flap presents an acceptable choice for transsexual patients giving an excellent volume of the neophallus enabling simple urethral reconstruction and full penile prosthesis implantation.

Finally, metoidioplasty or phalloplasty, that is the question? The choice lies in satisfying the patient's desires and understanding their needs. Transgender surgeon plays a very important role in explaining the pros and cons of each procedure, considering each individual as unique case and presenting the best surgical option.

\section{Acknowledgements}

Funding: This work is supported by Ministry of Science and Technical Development, Republic of Serbia, Project No. 175048.

\section{Footnote}

Conflicts of Interest: The author has no conflicts of interest to declare.

\section{References}

1. Bizic MR, Stojanovic B, Djordjevic ML. Genital reconstruction for the transgendered individual. J Pediatr Urol 2017;13:446-52.

2. Wiepjes CM, Nota NM, de Blok CJ, et al. The Amsterdam Cohort of Gender Dysphoria Study (19722015): Trends in Prevalence, Treatment, and Regrets. J Sex Med 2018;15:582-90.

3. Dhejne C, Öberg K, Arver S, et al. An analysis of all applications for sex reassignment surgery in Sweden, 19602010: prevalence, incidence, and regrets. Arch Sex Behav 2014:43:1535-45.

4. De Cuypere G, Vanhemelrijck M, Michel A, et al. Prevalence and demography of transsexualism in Belgium. Eur Psychiatry 2007;22:137-41.

5. Monstrey S, Houtmeyers P, Lumen N, et al. Radial forearm flap phalloplasty. In: Djordjevic M, Santucci R. Editors. Penile reconstructive surgery. Saarbrucken: LAP Lambert Academic Publishing, 2012;254-78.

6. Coleman E, Bockting W, Botzer M, et al. Standards of care for the health of transsexual, transgender, and gender nonconforming people, version 7. Int J Transgend 2012;13:165-232.

7. The World Professional Association for Transgender Health. Standards of Care for the Health of Transsexual, Transgender, and Gender Nonconforming People. 7th Version, 2011. Available online: http://www.wpath.org

8. Monstrey SJ, Ceulemans P, Hoebeke P. Sex reassignment surgery in the female-to male transsexual. Semin Plast Surg 2011;25:229-44.

9. Morrison SD, Perez MG, Carter CK, et al. Pre- and postoperative care with associated intra-operative techniques for phalloplasty in female-to male patients. Urol Nurs 2015;35:134-8.

10. Lebovic GS, Laub DR. Metoidioplasty. In: Ehrlich RM, Alter GJ. editors. Reconstructive and plastic surgery of the external genitalia. Philadelphia: WB Saunders Co, 1999:355-60.

11. Hage JJ, van Turnhout AA. Long-term outcome of metaidoioplasty in 70 female-to-male transsexuals. Ann Plast Surg 2006;57:312-6.

12. Perovic SV, Djordjevic ML. Metoidioplasty: a variant of 
phalloplasty in female transsexuals. BJU Int 2003;92:981-5.

13. Djordjevic ML, Bizic MR. Comparison of two different methods for urethral lengthening in female to male (metoidioplasty) surgery. J Sex Med 2013;10:1431-8.

14. Djordjevic ML, Bizic M, Stanojevic D, et al. Urethral lengthening in metoidioplasty (female to male sex reassignment surgery) by combined buccal mucosa graft and labia minora flap. Urology 2009;74:349-53.

15. Stojanovic B, Djordjevic M. Anatomy of the clitoris and its impact on neophalloplasty (metoidioplasty) in female transgenders. Clin Anat 2015;28:368-75.

16. Stojanovic B, Bizic M, Bencic M, et al. One-stage genderconfirmation surgery as a viable surgical procedure for female-to-male transsexuals. J Sex Med 2017;14:741-6.

17. Williams P, Bannister L, Berry M, et al. Gray's Anatomy. 38th edition. New York: Churchill Livingstone, 1995.

18. Djordjevic ML, Majstorovic M, Stanojevic D, et al. Combined buccal mucosa graft and dorsal penile skin flap for repair of severe hypospadias. Urology 2008;71:821-5.

19. Djordjevic ML. Hypospadias surgery: Challenges and Limits. New York: Nova Science Publishers Inc, 2014.

20. Markiewicz MR, Lukose MA, Margarone JE 3rd, et al. The oral mucosa graft: a systematic review. J Urol 2007;178:387-94.

21. Bogoraz N. Plastic construction of penis capable of accomplishing coitus. Zentral Chir 1936;63:1271-6.

22. Chang TS, Hwang WY. Forearm flap in one-stage reconstruction of the penis. Plast Reconstr Surg 1984;74:251-8.

23. Gilbert DA, Jordan GH, Devine CJ Jr, et al. Microsurgical forearm "cricket bat transformer" phalloplasty. Plast Reconstr Surg 1992;90:711-6.

24. Djordjevic ML, Bumbasirevic MZ, Vukovic PM, et al. Musculocutaneous latissimus dorsi free transfer flap for

Cite this article as: Djordjevic ML. Novel surgical techniques in female to male gender confirming surgery. Transl Androl Urol 2018;7(4):628-638. doi: 10.21037/tau.2018.03.17 total phalloplasty in children. J Pediatr Urol 2006;2:333-9.

25. Monstrey S, Houtmeyers P, Lumen N, et al. Radial forearm flap phalloplasty. In: Djordjevic M, Santuci R. editors. Penile reconstructive surgery. Saarbrucken: LAP Lambert Academic Publishing, 2012:254-78.

26. Sadove RC, Sengezer M, McRoberts JW, et al. Onestage total penile reconstruction with a free sensate osteocutaneous fibula flap. Plast Reconstr Surg 1993;92:1314-23.

27. Bettocchi C, Ralph DJ, Pryor JP. Pedicled pubic phalloplasty in females with gender dysphoria. BJU Int 2005;95:120-4.

28. Descamps MJ, Hayes PM, Hudson DA. Phalloplasty in complete aphallia: Pedicled anterolateral thigh flap. J Plast Reconstr Aesthet Surg 2009;62:e51-4.

29. Doornaert M, Hoebeke P, Ceulemans P, et al. Penile reconstruction with the radial forearm flap: An update. Handchir Mikrochir Plast Chir 2011;43:208-14.

30. Garaffa G, Christopher NA, Ralph DJ. Total phallic reconstruction in female-to-male transsexuals. Eur Urol 2010;57:715-22.

31. Baudet J, Guimberteau J, Nascimento E. Successful clinical transfer of two free thoraco dorsal axillary flaps. Plast Reconstr Surg 1976;58:680-8.

32. Djordjevic ML, Bizic MR, Stanojevic D. Phalloplasty in female-to-male transsexuals. In: Djordjevic M, Santucci R. editors. Penile reconstructive surgery. Saarbrucken: LAP Lambert Academic Publishing, 2012:279-304.

33. Djordjevic ML, Kojic S, Stojanovic B. Female-to-male gender affirmation phalloplasty. In: Salgado CJ, Monstrey SJ, Djordjevic ML. editors. Gender affirmation: Medical and surgical perspectives. New York: Thieme Medical Publishers Inc, 2017:155-70. 